Article

\title{
Searching for the Hidden: A Phenomenological Study Exploring the Spiritual Aspects of Day Case Surgery from Staff Perspectives
}

\author{
Joanne Pike \\ Department of Social and Life Sciences, Glyndŵr University, Mold Rd, Wrexham LL11 2AW, UK; \\ j.pike@glyndwr.ac.uk \\ Academic Editors: Fiona Timmins and Wilfred McSherry \\ Received: 20 September 2016; Accepted: 5 January 2017; Published: 19 January 2017
}

\begin{abstract}
Recent healthcare literature has shown an increasing interest in spiritual care and the way in which it supports patients as they deal with illness; but; as the body of evidence grows in many areas; the spiritual aspects of day surgery have been under-researched. The aims of this interpretive phenomenological study were to identify the patients' spiritual needs and concerns prior to surgery both from the patients' and surgical healthcare staffs' perspectives and to investigate whether there was congruence between the groups. The results of the staff focus groups are presented here. A purposive; convenience sample of 13 staff (nurses; consultants and pharmacists) attended one of three focus groups. Data were analysed utilising interpretive phenomenological analysis in order to discover the meaning for participants derived from their own contexts. Caring for spiritual and existential concerns was expressed through staff's relationships with patients; by a caring attitude and connection with them; helping patients to cope. Results show that spiritual care can be embedded in day surgery practice; and can be given during fleeting care episodes; though awareness is needed of the way in which this can be achieved.
\end{abstract}

Keywords: spiritual care; day case surgery; caring; connection; lived experience; interpretive phenomenological analysis

\section{Introduction}

This study is underpinned by the philosophy of Paul Tillich [1] in order to consider spirituality and the creation of meaning in the context of the needs and concerns of patients as they approach day case surgery. The study also utilised Smith, Flowers and Larkin's [2] interpretive phenomenological method. The research explored the embodied, human, lived experience of what it is like to be waiting for the planned surgical event. The rationale for this exploration is the increasing prevalence of day case surgery that Mottram described as "like a trip to McDonald's" ([3], p. 165) potentially to the detriment of the patient's spiritual needs.

Current research often associates the provision of spiritual care with the ability to spend time with the patient [4] which is not possible in the day case surgery setting since patients have a short and "ever-decreasing window of opportunity for nurse/patient interaction" ([5], p. 1022). Although previous research has investigated patients' perceptions of the preoperative period, and finds that patients' anxieties are exacerbated by the preoperative wait $[3,5,6]$, the spiritual concerns of day case surgery patients have not previously been explored from either the perspective of the patient or the staff. The 'hidden' or little discussed spiritual aspect of surgical care will be of primary concern to this article, since managing spiritual distress is an important part of holistic care as noted by Abbas and Dein [7]. This article will address the research gap, and aims to identify surgical staff perceptions of the preoperative phase with reference to existential concerns and spiritual care. Because 
spirituality is an integral part of the holistic approach to care and may be considered a 'hidden' concept, the research question is also a holistic one: How will the surgical team describe the patient's pre-operative experience from a spiritual perspective?

\section{Background}

Day case surgery patients often attend in order to receive targeted intervention (surgery) aiming to repair, to remove (or sometimes to sample, in the case of diagnostic surgery), or to restore function to a defective, or non-functional body part. This perspective may be interpreted as dualistic in approach, since it divides the body into psyche and soma, or alternatively, as led by Cartesian concepts, objectifies the body as a machine [8]. This infers that modern medicine can 'fix' a body part, ensuring a technical approach to diagnosing and treating the illness [9]; a rational, reductive process. While this separation of mind and body persists in modern medicine "it keeps clinicians, for the most part, from appreciating how illness affects patients" ([10], p. xii). If this is true, there may be a conceptual gap between holistic care and the actual care received by the patient undergoing day case surgery.

Patients approaching day case surgery are often anxious, with $85 \%$ reportedly anxious on the day of surgery [6] but emotions such as anxiety and suffering in day case surgery patients have been understudied. When addressing the suffering (or fearful) patient, Cassell [10] states that health professionals should not separate suffering and the concept of the person, nor reduce the sick person to physical and psychosocial dimensions. While this is the concept underpinning holistic care, the patient approaching day surgery may not appear to be suffering, so that they seem ostensibly to be 'well', or rather, not 'ill'. Furthermore, certainly in comparison with patients undergoing surgery which is more invasive or extensive, and therefore more 'serious', the day case surgery patient may not be seen as suffering in the same way [11], with health care professionals reserving the labour of emotional investment for those undergoing more major procedures [12]. Conversely, however, authors have demonstrated a need for holistic care for patients undergoing day case surgery [13]. The concept of spirituality as an intrinsic component of holism has been increasingly studied in the last ten to fifteen years, but it may be questioned whether spirituality is a meaningful paradigm for staff caring for patients undergoing day case surgery. The large body of ever increasing literature on the subject would suggest that health professionals consider it appropriate and authentic to give spiritual care in many settings, and in fact that it is unethical not to provide spiritual care where there is a recognised need to do so $[14,15]$.

This study investigates whether spirituality is a recognised need in the context of day case surgery; in particular, what staff consider provides 'meaning'. The concept of spirituality for this study is taken from the work undertaken by Clarke [16] who identifies that 'meaning' should be qualified by the term 'ultimate concern' after Tillich [17] in order to define the conditions under which meaning can become spiritual. This is the point at which reflecting on issues of ultimate concern is to consider something unconditional, holy, absolute, or as Clarke interprets Tillich-'the meaning of life'. For patients facing day case surgery, of the many aspects that cause fear, fear of death has been identified as the ultimate fear [18] so that, as will be seen below, facing day case surgery is an ontological question of the deepest sense and demonstrates that spiritual aspects are indeed important to patients at this point. Indeed, when the person is under stress, spirituality has been said to come to the fore [19].

This paper reports the perceptions of the surgical staff of the spiritual needs of the patient. In doing so, a contextual understanding of the phenomenon of spirituality was sought through interpretation of the lived experience of approaching day surgery as described by the surgical staff from their perspective. Understanding the experience from staff perspectives allowed a picture to grow of the way in which the spiritual experience is understood and responded to by staff in the context of day case surgery. 


\section{Materials and Methods}

This study sought to identify whether the concept of spirituality was an element of the 'lifeworld' of a surgical patient and within the scope of practice of day case surgery staff. A qualitative approach was therefore appropriate, since it was considered that qualitative research allows the researcher to identify the scope of practice [20]. Further, in seeking to comprehend the position of spirituality as experienced by the participants, it was acknowledged that as it is an embodied experience, a hidden, transcendental dimension, the data may not at first reveal the concept of spirituality.

The aim of the phenomenological approach is to interpret the lived experiences of people in an inductive way, which results in the development of theory from the exploration of empirical data. Thus, it is a mode of enquiry congruent with the individualised, holistic approach advocated in nursing [21]. Since phenomenology is a qualitative approach that seeks to give an existential account of human being, and to show how people structure their worlds [22], the phenomenological approach is ideally suited to understanding how to care for the embodied person, and understanding is considered a powerful tool for "becoming more effectively, skillfully, or humanely engaged in practice" ([23], p. xv). Since an understanding of the experience of approaching day case surgery is sought in this research, phenomenology was identified as the research method of choice. The methodology is that of a critical enquiry, so that data are subject to the hermeneutic process, the breaking down and re-structuring the data in order to articulate the meanings that are within [24].

Interpretive Phenomenological Analysis [2] was ideal for this research, since the individuals' situatedness, as has been evidenced by the results, 'hid' the phenomenon of interest-the participants' spiritual concerns within the lived experience of approaching surgery. Because interpretive phenomenology is concerned with the nature of the lived experience, how a person makes sense of that experience [25] and is an integrative approach, it was considered the most appropriate methodological framework to frame the research. The researcher attempts to study the lived experience, and tries to comprehend the meanings of that experience [22]. The experience is subjectively meaningful to the person who is undergoing it, and that person tries to make sense of it, from their own perspective. Interpretive phenomenology allows the researcher to interpret and analyse data from participants, but may go beyond the sense (meaning) made of the situation by the participants and may explore in detail the similarities or differences ('convergence' or 'divergence') within the participants' accounts [2]. There are disadvantages of this approach however, in that the researcher can focus on the text rather than the lived experience, and may not know when the interpretive process is completed [26].

Focus groups were held with nursing staff, allied health professionals and medical staff as the data collection method of choice, and discussions were focused on staff perceptions of patient's concerns prior to day case surgery. Although focus groups have been described as a less obvious method of data collection for interpretive methodological studies [2], they have been utilised by other phenomenological researchers $[27,28]$ and are capable of producing rich data.

\section{Results}

The staff perceptions of the patient experience are presented here; the results of the investigation into the patient's perspective will be presented in a separate article.

\subsection{Staff Perceptions of the Patient Experience}

During the focus groups, staff attempted to make sense of the patient experience, but also identified that they expected patients to be concerned, worried or afraid of something during the experience of day case surgery. Staff shared their views during three focus groups (Table 1). 
Table 1. The staff focus groups (FG).

\begin{tabular}{ccc}
\hline FG1 & FG2 & FG3 \\
\hline Angela & Emrys & Hannah \\
Barbara & Flyn & Iris \\
Carol & Grace & Jan \\
Diane & & Kathy \\
& & Lucy \\
& & Mai \\
\hline
\end{tabular}

Each of the 13 staff participants attended one of these. The presented results explore staff perceptions of the spiritual needs of the patient; their fears and anxieties. Other issues related to body image and the uncertainty of the outcome, but initial discussions centred on elements of the experience that staff considered would cause fear. Of note is the experience of fear in relation to the anaesthetic, and whether patients would survive it, which staff spent time discussing in their groups. Waiting was seen as problematic for patients, and staff also discussed, at some length, factors that might mediate patient's fears and anxieties.

\subsubsection{Fears and Anxieties}

Staff considered fear of the unknown to be one of the greatest fears of the patients, and expected patients to be anxious, since the outcome of the surgery could not be predicted, but also because day case surgery procedures were unknown to patients. As Jan (FG3) stated:

"it's an unknown entity isn't it?"

and Iris commented (FG3):

"and a lot of anxiety, fear of the unknown, like worrying about those things and the environment and not knowing what to expect and what's expected of you probably".

Other participants also discussed fear of the unknown as a contributory factor to patients' fears and anxieties as they approached their day case surgery. Patients were seen as especially fearful when diagnostic surgery was undertaken, or when they had heard reports in the press or from others that increased their fears. Staff expected patients to be fearful, despite the fact that during preparation for the surgical procedure, all patients had received information from anaesthetists, surgeons and nursing and pharmacy staff regarding their particular procedure.

Staff raised particular features of the surgical experience, with pain being considered an important aspect for patients. Pain was discussed as being a reason for seeking surgical intervention; for example, when a patient's pain was a symptom of an underlying disorder for which they were attending surgery. For these patients, comments such as:

"and all the terrible pains and discomforts that they have and that is such a relief then to have all relieved kind of thing" (Jan, FG3),

were reflected in a consensus among the participants in focus group one, with Barbara and Dianne considering surgery was positive a positive option for patients as it held the promise of pain relief. Staff also considered that patients thought about post-operative pain prior to their surgery, but opinions were divided on this, with some staff expressing that patients did not consider pain until the day of surgery. Interestingly, both perspectives on pain find parallels in the patients' results.

The anaesthetic was considered to cause fear for most patients, with staff considering the ultimate question of surviving the anaesthetic as the most worrying. As Barbara (FG1) noted:

"the majority of them are anxious about the anaesthetic on the day of the surgery not their procedure", 
while Grace (FG2), Jan and Mai (both FG3) all considered patients worried about dying under anaesthetic, with Jan reporting what one patient had asked her:

"one lady and she said to us a few weeks ago, 'Am I going to die, could I possibly die?', because she had a really very negative view of anaesthetic".

So it can be seen that fears and anxieties were considerable for the patients, in particular the fear of dying under anaesthetic.

\subsubsection{Attitudes and Outcomes}

Linked to the fear are patients' attitudes to surgery. Staff noted that these were variable, with some patients, especially those who had previously had surgery or knew more about their surgery, thought to be more relaxed in their approach. Although, as Iris (FG3) stated, the opposite was true in her opinion:

"And some say, 'I'm nervous', and yet they've been through operations before and they say, 'Oh, it doesn't get any easier'. It doesn't really, does it, it doesn't matter how many times they come into hospital, it doesn't get any easier for them when they come for something else or the same thing does it?"

Staff considered that information was important in allaying fears and while some patients wished for a lot of information, others wanted very little information. Carol (FG1) considered this distinction:

“I've had some people say to me, 'I don't want to know anything, don't tell me, I don't want that leaflet', and you're thinking, 'Oh dear, but you need to know, there are some things you do need to know'. They might find out as they go along but I think it should be as to regards how much they can take in, how much they want to know".

There was no consensus of opinion on this point between the staff respondents, though information giving was still considered important.

The possible outcome of the surgery was also considered an important factor in the way in which patients approached their surgery. Some patients were said to have a pragmatic approach and hence were thought to worry less, while others who were having diagnostic surgery were thought to have to 'prepare' themselves for what was to come. As Jan (FG3) stated:

"And if it's something diagnostic it could alter the whole way of thinking, it could alter their whole way of life, their mode of living and [they've] got to be prepared for this, they've got to prepare themselves really for good news or bad news".

So it can be seen that those patients who had to 'prepare' themselves in order to cope with diagnostic surgery, were dealing with the potential of life-altering news post operatively. Surgery could bring good or bad news, requiring patients to hope for good news, but also find ways of coping with the potential for bad news. Coping often meant seeking support from others, since connecting with a significant other, and at times the staff, provided strength and fostered the ability to cope.

\subsubsection{Body Image}

Body image was another stressful aspect, seen to affect the patients' responses to the day surgery procedure. Visible scarring was considered as threatening to a person's body image, and could contribute to the fear of the surgery, Jan (FG3) stated:

"We've had removals of cysts and some nasty things you know when it's all very scary".

Body image issues such as wearing hospital gowns in public and removing makeup, prostheses and dentures were also discussed as concerning for the patients; Diane (FG1) noting: 
"and the lady the other day who was wearing a wig and she said, 'will I have to remove this?' And you know, so they do worry about their dentures and everything, things like that",

demonstrating that staff understood patients' concerns. Other staff members considered the issue more deeply, considering patients' identities and how this was stripped away, so that ultimately, the patient was wearing a shapeless piece of material (the theatre gown) with very little else. Three participants in focus group three discussed this, and Jan summed up the conversation noting:

"All of that impacts on their body image doesn't it you know? How they feel about themselves, which is vulnerable, very vulnerable aren't they".

In stating this, Jan noted the way in which body image, the threat to self and personhood are linked, increasing vulnerability and causing suffering.

\subsubsection{Waiting}

Waiting was another concern for patients, with staff discussing the uncertainty for patients of how long they had to wait. Staff shared that patients asked about their position on the surgical list and 'worked out' approximately how long they would need to wait. Flyn (FG2) noted that patients did not like waiting, and especially when the surgeon adjusted the order of the list, which, though it was not 'ideal', was inevitable due to the needs of the other patients. Waiting was particularly problematic the longer the patient had to wait, since as Flyn added:

"and of course, if they were anxious to start with, well they are a lot more anxious at 12.30".

Although staff considered that this was not an ideal situation, Flyn stating:

"They don't like waiting".

Staff did not know how this could be altered, and it was considered that waiting was necessary for some patients in order for the theatre list to run smoothly. Katy (FG3), however, noted that there was a potential for anxiety to increase during the waiting time, and especially so when staff were busy:

"and they are just sat there waiting for theatre, and nobody's been to (see) them in that time and said, 'Oh well, you know', and I think that gets a lot of people really worked up".

The situation was different when the patients were on the ward waiting rather than in the waiting room, because staff could see the patients' responses and react to them when they became concerned. Staff understood that the environment made a difference to patients' ability to manage their stress and Mai (FG3) considered it was good for the patients to talk to one another, because it made them feel more relaxed, Jan (FG3) commenting:

"they feel that bond with the other person ... as if they have known each other for ages because they're all in the same boat so to speak".

Jan's comment speaks eloquently of the power of a spiritual connection with another and the comfort that being part of a communal experience can bring, while Amy (FG1) observed:

"They will talk to each other and we've commented when we've had a really nice day,

'Gosh, all the patients have been talking and interacting today!' and stuff like that"

identifying that the staff also derived comfort from the relaxed atmosphere. The discussion in focus group three identified that during periods when there was little interaction between the patients in the waiting room, the atmosphere became more tense, so that when staff entered the waiting room, as described by Iris (FG3):

"You've got eyes watching you", 
while Mai added (FG3):

"You can feel eyes on you all the time"

indicating that the patients were seeking comfort and reassurance from the staff.

\subsubsection{Mediating Factors}

Thought to support patients with their fears and anxieties, mediating factors were considered by staff as important. Trust was the most important factor, with staff identifying that patients had trust in the National Health Service (NHS) in general, but trusting the surgeon who would be undertaking the procedure had a great influence on the patient's concerns. Furthermore, with reference to the whole experience, Diane (FG1) stated:

"I mean really that person is putting their life in your hands really. It's a big trust, they have to trust".

Staff in focus groups one and two also discussed trust as a human factor that they believed may influence doubts about going ahead with the surgery. Contrary to Diane's statement above, Grace (FG2) considered that the majority of patients trusted most staff in the NHS, inferring that no one surgeon was trusted more than another. However, staff considered that trust was important, since their relationships with patients were founded on trust. Staff were anxious to maintain this trust, in order to maintain their relationships with them, therefore acknowledging the vital importance of those relationships to the patient.

\subsection{Staff Responses to the Patient Experience}

Staff were able to care for patients undergoing day case surgery by supporting them, and recognising and responding to anxiety and fear, demonstrating an underlying philosophy which appeared to guide their approach. It was not the aim of the research to ask staff about their interventions, but they arose as part of the focus group interviews. As part of the discussion, staff disclosed some of the difficulties faced when determining whether the signs that patients were displaying were attributable to anxiety. This aspect will be addressed first in this section.

\subsubsection{Is It Anxiety?}

The first consideration for staff, before they could intervene to help the patient was whether the emotions displayed constituted anxiety. Kathy (FG3) was concerned that it was not always possible to recognise anxiety when a particular behaviour was manifest. She said:

"And their anxieties come across in different ways as well. They can be a bit aggressive and things if they are really anxious about things ... you don't always realise they are anxious, you just think they're being aggressive sometimes".

And Mai (FG3) agreed, stating:

"You find them a bit aggressive and yet then later on in the afternoon, they're a lovely person and you think, 'Oh, right!'”,

identifying that the observed reduction in the anxiety levels in the individual following surgery, meant that they were able to attribute previous aggression to anxiety prior to surgery. Jan (FG3) noted that it was sometimes difficult to empathise with some manifestations of anxiety, but:

"because that's part of our job really ... just discover if there are any anxieties, then we can allay them, kind of thing".

In her explanation, Jan reflected that that she wanted to connect meaningfully with her patient, in order to provide the support that she felt they needed, but that this was not always possible because patients did not always express their anxieties. Furthermore, as Lucy (FG3) noted: 
"Some people will tell you how they've been feeling prior to coming in, but others sort of bottle it up, I suppose".

And Jan (FG3) replied:

"You don't always suss them out because they're good actors you know. And they're doing it for themselves, I mean a lot of us say, it's like somebody says to you, 'Oh, how are you today?' and you say, 'Oh, I'm fine!' but you've got a cold, or you are really actually down".

Despite this stoical approach, staff understood that patients needed them, and wished to connect with them. In order to do this, staff looked beyond the stoicism in order to support them through the surgery, helping patients to make sense of the situation.

\subsubsection{Supporting the Patient by Being with Them}

Spending time with patients was also considered important, though this was dependent on how busy the ward was. During quieter periods, Lucy (FG3) noted that there was more time to be with the patient in a meaningful way:

"But when we're obviously not busy we can spend much time with them so depending how busy the ward is, this affects our way with the patient".

Not all patients hid their anxiety however, with some patients exhibiting a great deal of anxiety and staff interventions were to encourage the patient to think of something else, so distraction techniques were frequently used. Barbara (FG1) noted:

"what's the point in me saying, yes it's going to be alright, and it's not going to make a scrap of difference as to how you are feeling, so let's just chat about something else instead."

However, there was an expectation that despite trying to be supportive and to employ distraction techniques, patients would remain anxious to a greater or lesser extent. Participants also acknowledged that even though the patients were nervous, staff were unable to alleviate their anxieties completely. Jan (FG3) was eloquent in her explanation:

"Regardless of how supportive we are, how helpful we are, those anxieties will remain to a greater or lesser extent, those fears. You can't erase them because it's like people who are dying, or a woman having a baby or whatever. You do it alone, even though there are people helping you, or meaning to support you and understand how you feel. Maybe just understanding how you feel, and get the point, that's something isn't it?"

Here, Jan echoed what was being discussed in the focus group, that having an understanding was a help in some way to the patient, and that the shared perspective between the patient approaching surgery and the nurse promoted a meaningful spiritual connection to be created between them. A spiritual connection such as this has true therapeutic potential. As Jan explained:

"The philosophy behind that is to give as much support as we can to the patient, you know, make them feel relaxed and at ease you know".

\subsubsection{Information}

There was much discussion in each of the three groups as regards giving information. Staff considered this very important in alleviating anxiety, but they noted that it was also important to gauge how much information the patient needed or wanted. This was a difficult task at times, as along with the information regarding the surgery, risks were also explained to patients. As well as providing some reassurance, explaining risks was seen as worrying patients, especially when those risks were written down. Grace (FG3) noted: 
"Sometimes I worry about giving out information leaflets because there is just so much information on them that they can scare people a lot",

while Emrys (FG2) considered how important it was not to scare patients but to consider their needs carefully when discussing information. Emrys also noted that he did his best to meet patients' information needs, so that if they were unhappy with the information they had received:

"then normally you take a few minutes to try and find out what the problem is, again within the bounds of time".

At times, things did not go well during the patient's journey, and all three focus groups considered that keeping the patient informed was imperative. Amy was able to give a good account of how staff dealt kindly with patients when their surgery was postponed:

"It's a personal touch. If you can go and speak to them directly right, yes they are (upset). It hadn't gone to plan, but because I'd gone there personally, and given them an explanation, I think that's a lot to do with it rather than just saying to them, 'I'm sorry we've got to cancel you. Bye, we'll call you'"'.

Staff wanted the best for their patients and felt responsible for their experience, so keeping them informed about the progress of the surgical list was important, especially when patients were already nervous. This again was an indication of the therapeutic relationship that staff believed in and which supported their spiritual philosophy of care.

\subsubsection{Holistic Approach}

While so much of the preparation for surgery was intended to manage the physical risks of undergoing surgery under anaesthetic, participants wanted to point out that caring for patients was not just about physical care. Diane (FG1) explained that staff listened to each patient, assessing them holistically, while Jan (FG3) noted that each patient was unique, underpinning their belief in holistic care and valuing patients' personhood. Iris discussed one patient who Kathy noted (FG3) had been 'trying to hide it all by being loud and chatty' saying that:

"he was quite emotional, and when we actually got to theatre he was tearful".

Iris explained that he was a carer for his wife and he confided in her that he was worried about what would happen to her if anything happened to him under anaesthetic.

From this discussion, it can be seen that staff cared deeply about their patients and how they were coping with the experience. Diane (FG1) said:

"I never worry about the care that they're going to get or anything like that. I know that they're going to be alright, you know, but you still think about them don't you?"

While Barbara (FG1), in reply, reasoned that she cared for each of her patients:

“That's because you've met them, haven't you, so they'll have expressed their anxieties or thoughts and feelings to you".

The staff discussed the patients as people with whom they developed a meaningful relationship and explained their connection with them. Barbara gave an example of this:

"But you've got that relationship with them ... they share things with you that they don't share with anybody else. And we had a lovely couple ... and she was pregnant and she was about six weeks, eight weeks and she hadn't told any of the family and yet they shared it with us and I thought how lovely was that? For a day case patient that you know for a couple of hours". 
And Carol (FG1) commented in reply:

"They see us as the medical profession and they're quite happy just to say, they do tell you everything and anything don't they?"

This shows that a spiritual connection was made with the patient that was deep enough to encourage patients to share information that was often deeply personal. The staff felt privileged to be trusted with it, reverently acknowledging the way in which patients shared their secrets and depended on them.

The relationship between staff and patients was important in developing a holistic view of the patient, in enabling a connection to be made between staff and patients, and helping to promote patient trust. At times, the connection was made very strongly and patients felt that they could share some intensely personal information in the safe, caring space created. From the discussions presented, staff understood that anxiety was expressed in many different ways, describing the ways in which they ensured each patient received supportive holistic and spiritual care. Importantly, the spiritual way of being underpins all of the caring attention administered by the surgical staff. During the discussions, it appeared as the vital and central component of day surgery care.

\section{Discussion}

\subsection{Holism}

The caring professions have long claimed a holistic view point of the patient, in other words, viewing the patient not as though they are separate components of body, mind and spirit, but that these are indivisible from one another and therefore one [29]. If the professional intends to care for the whole person, it would seem that they have a deontological duty (that it is ethically right) to give spiritual care [14] and in fact, it could be considered unethical not to provide spiritual care [15], in particular where a need has been recognised. During the interpretive process of the data analysis, spirituality has been considered not only as a part of the whole, but as an inseparable part of the whole. Spirituality has therefore been considered as embodied within the patient experience.

Since this research investigates the spiritual aspects of preoperative care, findings were not corroborated by other similar research, although research into the spiritual aspects of major surgery have been carried out [30-32] and have been shown to be important. What is exciting about this research is that spirituality in the day surgery context is found within the staff's expressions of the ways in which they cared for the patients. Their language expressed how making a caring connection with the patient was important and demonstrated their spiritual approach to caring in the day case surgery context. As such, they demonstrated that it is possible to offer spiritual care very simply as part of being with the patient in a loving and caring fashion [33]. This has also been found by many other writers in varying health contexts. Miner-Williams [34], for example, asserts that spiritual care can be given in a spiritual manner through establishing a caring relationship and practising the art of being present, listening and supporting the patient's beliefs and values and through making a connection with the patient. Connecting with the patient, particularly in times of stress has been identified as significant in supporting the patient to cope [35,36]. Among many other writers, Clarke [37] supports the fact that spiritual care is not to be separated from care, but that it is based on relationships with patients and within the context of providing for physical care needs.

\subsection{Fears and Anxieties}

In this study, staff perceived that the patients' fears and anxieties were often observable, since they were manifest by most patients as they approached surgery. Some patients expressed their fears of dying under the anaesthetic (also found by Mitchell [38]), but not all patients admitted to feeling like this. In contrast, some patients were very calm, appearing to have no anxieties about their surgery. Staff found that patients were worried in particular about the anaesthetic, a finding that resonates with 
Mitchell's studies on anxiety and local and general anaesthesia $[36,39,40]$, and which appeared to be the most prominent fear on the day of surgery. Staff discussed how they addressed patients' needs, describing interventions that they applied to their perceptions of their patients' needs. Of greatest concern to staff was to respond to patient's anxieties, although they sometimes found that it was difficult to determine whether a patient's behaviour was due to anxiety. At times, when patients were found to be aggressive, staff would deal with the aggression, but it was not until after the surgery was over, that the staff realised that the aggression was due to a patient's anxiety. As well as outwardly emotive patients, some patients had a tendency to repress their emotions but staff understood that these patients were no less anxious than others who expressed their emotions more openly.

Staff responded to anxiety in a number of ways, principally by employing distraction techniques and talking to patients about day-to-day matters, rather than about the more serious concern of the surgery. Staff understood that some patients needed more care than others, and they invested more time in these patients. Patients were given information in order that they could understand what was going to happen to them, in an effort to reduce stress and enhance coping, as identified in a study on information giving to reduce anxiety by Stoddard, White, Covino and Strauss [40]. While staff realised that each patient had individual needs in terms of the volume and depth of information, they recognised that it was not always possible to meet each patient's needs for information fully. This was often due to time constraints during appointments, and on the day of surgery. Staff understood that the care of patients being admitted for day surgery entailed caring for patients as individuals, with individual needs. They understood that psychological and sociological concerns also impacted on the patients as they approached surgery, but were not aware of their impact on the patient's spiritual needs.

\subsection{Connecting and Trust}

A positive finding was that staff considered that some patients built up a trusting relationship very quickly with them, and were willing to share intimacies with them, which showed the level of trust placed in staff. The level of connection with staff is evidence of an openness of the part of the patients to relate closely to the staff during their time of need. Trust was a factor that Demir, Donmez, Ozsaker and Diramali [41] found was enhanced when information about the surgical procedure was given to patients, a factor that staff thought they did quite well. Trust has been found to be created when relationships are built, and this, states Carr [42], is the foundation of spiritual caregiving. As can be seen here, staff took care to intentionally build relationships in order to support patients through the surgical experience.

\section{Conclusions}

The uniqueness of this study has provided new insights into the nature of spirituality as it is embedded in the responses by staff to patients undergoing day case surgery. One of the most important findings is that staff are able to form a relationship with patients that is nurturing and supportive in a very short space of time. Previous spiritual care research has identified that in order to care for a patient spiritually, relationships must be built up over time [43]. Although staff recognised the nature of the trusting relationships forged at this time, the spiritual nature of caring connectedness that has such therapeutic potential [44], was not recognised by staff. Yet, staff remembered particular patients that demonstrated how profound and intimate relationships can be developed during this short therapeutic episode, and identified how privileged they were to have intimate secrets shared with them. To be spiritual in the context of caring in day case surgery is to express a willingness to connect with the patient, and to affirm the patient as a person, respecting them and acknowledging the privilege of providing care to the patient during their vulnerability. Helping patients to cope in a spiritual sense, therefore, is to identify their ultimate concerns as they approach surgery. To be spiritual in the context of the patient undergoing day surgery, is to be able to express themselves to the staff and to have those expressions attended to and affirmed by the day surgery staff. 
If care providers can identify with these conceptualisations of spirituality in the context of day case surgery, then the action of internalising the wish to care for the people as persons and to connect with them is to care for them spiritually. Caring spiritually is a moral imperative, and is an unconditional giving of oneself to a relationship that is an outcome of the embodiment of spiritual and moral values. Furthermore, the difference between giving care, and giving care spiritually, is establishing a caring connectedness with an intentionality [45] that acknowledges the spiritual nature of the interaction, though neither party may call it that. In the context of day case surgery, spiritual care is about being with the patient, making a little space and giving a little time, and as has been described in the literature, is giving care spiritually rather than giving spiritual care [34].

\section{Recommendations}

The recommendations for practice arising from this study are concerned with raising the awareness of staff caring for day case surgery patients, to be aware that these patients may well have spiritual needs that are embedded in their worldview and therefore not readily visible to themselves or to others. The spiritual aspect of the patient may not be visible as a separate entity, but it may find its expression in what is important to the patient or in their relationships with others. In the day case surgery setting, spiritual expressions may be connected with existential aspects or with fear and patients may wish to connect with the surgical staff. Staff should be aware of this, since at present, the results of this research indicate that staff are not always aware of their therapeutic potential, a finding that has been identified previously by Mottram [18].

Acknowledgments: With thanks to the Research Capacity Building Collaboration (Wales) for providing funds to support this study towards $\mathrm{PhD}$. No funding has been received to publish this article in open access.

Conflicts of Interest: The author declares no conflict of interest. The funding sponsors had no role in the design of the study; in the collection, analyses, or interpretation of data; in the writing of the manuscript, and in the decision to publish the results.

\section{References}

1. Arthur F. Holmes. "The Role of Philosophy in Tillich's Theology." Bulletin of the Evangelical Theological Society 10 (1967): 161-71.

2. Jonathan A Smith, Paul Flowers, and Michael Larkin. Interpretive Phenomenological Analysis; Theory, Method and Research. London: Sage, 2009.

3. Anne Mottram. "Like a trip to McDonalds: A grounded theory study of patient experiences of day surgery." International Journal of Nursing Studies 48 (2011): 165-74. [CrossRef] [PubMed]

4. Barry S. Gallison, Yan Xu, Corrine Y. Jurgens, and Suzanne M. Boyle. "Acute care nurses' spiritual care practices." Journal of Holistic Nursing 31 (2013): 95-103. [CrossRef] [PubMed]

5. Mark Mitchell. "Influence of gender and anaesthesia type on day surgery anxiety." Journal of Advanced Nursing 68 (2012): 1014-25. [CrossRef] [PubMed]

6. Mark Mitchell. "General anaesthesia and day-case patient anxiety." Journal of Advanced Nursing 66 (2010): 1059-71. [CrossRef] [PubMed]

7. Sayed Q. Abbas, and Simon Dein. "The difficulties assessing spiritual distress in palliative care patients: A qualitative study." Mental Health, Religion \& Culture 14 (2011): 341-52. [CrossRef]

8. Charles Lowney. "Rethinking the machine metaphor since Descartes: On the irreducibility of bodies, minds, and meanings." Bulletin of Science, Technology and Society 31 (2011): 179-92. [CrossRef]

9. Shawn Pohlman, Nancy J. Cibulka, Janice L Palmer, Rebecca A Lorenz, and Lee SmithBattle. "The placebo puzzle: Examining the discordant space between biomedical science and illness/healing." Nursing Inquiry 20 (2013): 71-81. [CrossRef] [PubMed]

10. Eric J. Cassell. The Nature of Suffering and the Goals of Medicine, 2nd ed. New York: Oxford University Press, 2004.

11. Merri Koivula, Marja-Terttu Tarkka, Matti Tarkka, Pekka Laippala, and Marita Paunonen-Ilmonen. "Fear and anxiety in patients at different time-points in the coronary artery bypass process." International Journal of Nursing Studies 39 (2002): 811-22. [CrossRef] 
12. Lynne Wigens. "The conflict between 'new nursing' and 'scientific management' as perceived by surgical nurses." Journal of Advanced Nursing 25 (1997): 1116-22. [CrossRef] [PubMed]

13. Deniz Selimen, and Isil Isik Andsoy. "The importance of a holistic approach during the perioperative period." AORN Journal 93 (2011): 482-87. [CrossRef] [PubMed]

14. Barbara Pesut, and Sally Thorne. "From private to public: Negotiating professional and personal identities in spiritual care." Journal of Advanced Nursing 58 (2007): 396-403. [CrossRef] [PubMed]

15. Margaret A. Burkhardt. "Commentary on 'Existential and spiritual needs in mental health care: An ethical and holistic perspective'." Journal of Holistic Nursing 27 (2009): 43-44. [CrossRef] [PubMed]

16. Janice Clarke. "A discussion paper about 'meaning' in the nursing literature on spirituality: An interpretation of meaning as 'ultimate concern' using the work of Paul Tillich." International Journal of Nursing Studies 43 (2006): 915-21. [CrossRef] [PubMed]

17. Paul Tillich. "Religion and secular culture." In Paul Tillich: Theologian of the Boundaries, Selected Writings. Edited by Mark Kleine-Taylor. London: Collins, 1987, pp. 119-25.

18. Anne Mottram. "Therapeutic relationships in day surgery: A grounded theory study." Journal of Clinical Nursing 918 (2009): 2830-37. [CrossRef] [PubMed]

19. Carol Kronenwetter, Gerdi Weidner, Elaine Pettengill, Ruth Marlin, Lila Crutchfield, Patricia McCormac, Caren J. Raisin, and Dean Ornish. "A qualitative analysis of interviews of men with early stage prostate cancer: The Prostate Cancer Lifestyle Trial." Cancer Nursing 28 (2005): 99-107. [CrossRef] [PubMed]

20. Helen J. Streubert, and Dona Rinaldi Carpenter. Qualitative Research in Nursing, 5th ed. Philadelphia: Lippincott Williams and Wilkins, 2011.

21. Kathryn Weaver, and Joanne K. Olson. “Understanding paradigms used for nursing research.” Journal of Advanced Nursing 53 (2006): 459-69. [CrossRef] [PubMed]

22. Hubert L. Dreyfus. "Preface." In Interpretive Phenomenology: Embodiment, Caring and Ethics in Health and Illness. Edited by Patricia Benner. Thousand Oaks: Sage Publications, 1994, pp. vii-xi.

23. Patricia Benner. "Introduction." In Interpretive Phenomenology: Embodiment, Caring and Ethics in Health and Illness. Edited by Patricia Benner. Thousand Oaks: Sage Publications, 1994.

24. Joe L. Kincheloe, and Peter McLaren. "Rethinking critical theory and qualitative research." In The Sage Handbook of Qualitative Research Third Edition. Edited by Norman K. Denzin and Yvonna Lincoln. Thousand Oaks: Sage Publications, 2005, pp. 303-42.

25. Susann M. Laverty. "Hermeneutic phenomenology and phenomenology: A comparison of historical and methodological considerations." International Journal of Qualitative Methods 2 (2003): 21-29. [CrossRef]

26. Michael D. Myers. Qualitative Research in Business and Management. London: Sage, 2009.

27. Rhona MacLoed, David Craufurd, and Katie Booth. “Patients' perceptions of what makes genetic counselling effective: An interpretive phenomenological analysis." Journal of Health Psychology 7 (2002): 145-56. [CrossRef] [PubMed]

28. Paul Flowers, Mark Davis, Graham Hart, Marsha Rosengrten, Jamie Franks, and John Imrie. “Diagnosis and stigma and identity amongst HIV positive Black Africans living in the UK." Psychology E Health 21 (2006): 109-22. [CrossRef]

29. Aru Narayanasamy. "The impact of empirical studies of spirituality and culture on nurse education." Journal of Clinical Nursing 15 (2006): 840-51. [CrossRef] [PubMed]

30. Fabio Ikedo, Deepak M. Gangahar, Mohammed A. Quader, and Lynette M. Smith. "The effects of prayer, relaxation technique during general anesthesia on recovery outcomes following cardiac surgery." Complementary Therapies in Clinical Practice 13 (2007): 85-94. [CrossRef] [PubMed]

31. Darcy J. Ammerman, James Watters, Jennifer J. Clinch, Paul C. Hébert, Keith G. Wilson, Daniel B. Morris, and Dean Fergusson. "Exploring quality of life for patients undergoing major surgery: The perspectives of surgeons, other healthcare professionals, and patients." Surgery 141 (2007): 100-9. [CrossRef] [PubMed]

32. Jenny Rosendahl, Katharina Tigges-Limmer, Jan Gummert, Ralf Dziewas, Johannes Maximilian Albes, and Bernhard Strauss. "Bypass surgery with psychological and spiritual support (the By.pass study): Study design and research methods." American Heart Journal 158 (2009): 8-14. [CrossRef] [PubMed]

33. Rick Sawatzky, and Barbara Pesut. "Attributes of spiritual care in nursing practice." Journal of Holistic Nursing 23 (2005): 19-33. [CrossRef] [PubMed]

34. Denise Miner-Williams. "Putting a puzzle together: Making spirituality meaningful for nursing using an evolving theoretical framework." Journal of Clinical Nursing 15 (2006): 811-21. [CrossRef] [PubMed] 
35. Mark Mitchell. “Enhanced recovery programmes.” British Journal of Nursing 20 (2011): 978-98. [CrossRef] [PubMed]

36. Mark Mitchell. "Conscious surgery: Influence of the environment on patient anxiety." Journal of Advanced Nursing 64 (2008): 261-71. [CrossRef] [PubMed]

37. Janice L. Clarke. Spiritual Care in Everyday Nursing Practice. Houndmills: Palgrave Macmillan, 2013.

38. Mark Mitchell. "Patient anxiety and conscious surgery." Journal of Perioperative Practice 19 (2009): 168-74. [PubMed]

39. Mark Mitchell. “A patient-centred approach to day surgery nursing." Nursing Standard 24 (2010): 40-46. [CrossRef] [PubMed]

40. Jill A. Stoddard, Kamila S. White, Nicholas A. Covino, and Lisa Strauss. "Impact of a brief intervention on patient anxiety prior to day surgery." Journal of Clinical Psychology in Medical Settings 12 (2005): 99-110. [CrossRef]

41. Fatma Demir, Yelda Candan Donmez, Esma Ozsaker, and Alev Diramali. "Patients' lived experiences of excisional breast biopsy: A phenomenological study." Journal of Clinical Nursing 17 (2008): 744-51. [CrossRef] [PubMed]

42. Tracy J. Carr. "Facing existential realities: Exploring barriers and challenges to spiritual nursing care." Qualitative Health Research 20 (2010): 1379-92. [CrossRef] [PubMed]

43. Moon Fai Chan. "Factors affecting nursing staff in practicing spiritual care." Journal of Clinical Nursing 19 (2010): 2128-36. [PubMed]

44. Donia R. Baldacchino. "Teaching on the spiritual dimension in care: The perceived impact on undergraduate nursing students." Nurse Education Today 28 (2008): 501-12. [CrossRef] [PubMed]

45. Teri B. Pipe, Ann Kelly, Gail LeBrun, Don Schmidt, Pamela Atherton, and Carol Robinson. "A prospective descriptive study exploring hope, spiritual wellbeing, and quality of life in hospitalized patients." MEDSURG Nursing 14 (2008): 247-54.

(C) 2017 by the author; licensee MDPI, Basel, Switzerland. This article is an open access article distributed under the terms and conditions of the Creative Commons Attribution (CC BY) license (http:/ / creativecommons.org/licenses/by/4.0/). 